fiasco in which flaws in statistical procedures and maximum parsimony analysis of the mitochondrial DNA data using the PAUP computer program have been noted and the conflicting molecular evidence about whether the chimpanzeegorilla-human trichotomy is really resolved, or even resolvable, one 'genioglossus in vestibule' rejoinder to Sarich might be that "one no longer has the option of considering chimpanzees more closely related to humans than to gorillas no matter how good the molecular evidence superficially appears to be"!

To his credit, Leakey is not hung up on giving fossils specific names and seems to understand, unlike many of his peers, that just because one gives a specific name to a fossil does not necessarily mean that one has described a real biological species. The biological species concept is only operative in organisms where reproductive behaviour can be examined in nature (or the laboratory). Species-specific morphological distinctions can only be codified after species are so identified. The process does not work the other way round. One cannot first observe differences in fossils and then claim that these differences define true biological species because, as is well known, morphological differentiation and speciation are not necessarily correlated. One reason evolutionary scenarios are so contentious is that palaeoanthropologists continually name fossil species and then create scenarios based on the artificial constructs they have just created. So, for example, the discovery of the Black Skull may indeed force people to "change their minds", as Leakey and Lewin put it, about australopithecine phylogeny, but only those who bought into the 'orthogenetic' view of australopithecines as evolving linearly from $A$. africanus through $A$. robustus to A. boise i in the first place. For those of us who noted a decade ago that this scheme was unlikely, our views are now reinforced, not changed.

As a self-made man, Leakey has had to put up with a lot from his detractors, some of whom would undoubtedly concur with Disraeli that self-made men often tend to worship their creator. But I, for one, have a great deal of admiration for the man. Part of the reason is that, like me, he studies fossils the old-fashioned way - he tries to find them. But it is his passion for the African bush and the preservation of its vanishing wildlife that resonates most strongly with me. In this, the latest and most difficult challenge of his life, we all must see to it that he succeeds.

Glenn C. Conroy is in the Departments of Anatomy and Neurobiology, and of Anthropology, Washington University Medical School, St Louis, Missouri 63110, USA.

\section{Common-sense consciousness}

\section{Stuart Sutherland}

The Rediscovery of the Mind. By John R. Searle. MIT Press: 1992. Pp. 270. $\$ 22.50, £ 19.95$ (hbk); £9.95 (pbk). (Pbk not yet available in the US.)

JUST as the mini-skirt comes and goes in women's clothing, so does consciousness fluctuate in fashion for philosophers. In the past few years, bookshops have been graced or despoiled by shelf-loads of tomes devoted to the subject. Almost all have been turgid and obscurantist. Now, with The Rediscovery of the Mind we have a clear, well written and cogently argued account, which is marked by that unfashionable quality, common sense. In standing up for the existence of consciousness as a fact, John Searle attacks with pleasing acerbity the loonier beliefs of those who have attempted to deny it. For example, of the Churchlands, who claim that mental terms have been invented by ordinary people to explain behaviour ("folk psychology") and therefore have no validity, he asserts: "It is hard to come right out and say that no one ... ever drank because she was thirsty ... but it's easy to challenge something if you can label it in advance as "folk psychology'." And on other efforts to eliminate consciousness by regarding it as identical with a high-level account of certain brain operations, he writes, "If you are tempted to functionalism, I believe you do not need refutation, you need help".

Searle's own view is that "mental phenomena are caused by neurophysiological processes in the brain and are themselves features of the brain" and he rightly insists on the distinction between consciousness and behaviour or even, as Gilbert Ryle put it, dispositions to behave, for "a system could have consciousness without behaviour and behaviour without consciousness." All this is robust common sense and, I believe, unarguable.

Searle runs into trouble, however, when he attempts to specify the relation between consciousness and the brain. He writes, "Consciousness is a higher-level or emergent property of the brain in the utterly harmless sense of 'higher-level' or 'emergent' in which solidity is a higherlevel emergent property of $\mathrm{H}_{2} \mathrm{O}$ molecules when they are in a lattice structure (ice)", but he goes on to deny the reducibility of consciousness to brain function. But if solidity can be reduced to the behaviour of molecules, why cannot consciousness similarly be reduced to the behaviour of the brain of which it is an emergent property? Searle's answer is tortuous. He claims that solidity originally meant the feeling produced by a solid object: the reduction applies not to this feeling but to the property of the object that gives rise to the feeling. This argument does not work: if the solidity of an object can be reduced to the behaviour of its molecules and if the relation between consciousness and the brain is analogous to that between the solidity of an object and the state of its molecules, then surely consciousness should be reducible to brain states. The contention that consciousness is merely an emergent property of brain states cannot therefore be sustained. It is no use Searle arguing, as he does, that such phenomena as magnetism were irreducible before Maxwell and similarly that one day we will have a theory that shows how consciousness emerges from the brain. There must be, and indeed is, something special about consciousness if it is not reducible.

Searle is also weak on the evolution and function of consciousness. He thinks it allows us to make finer discriminations and has no hesitation in assigning to it a causal role in behaviour. But elsewhere he talks of two robots that behave identically, one of which is conscious (because

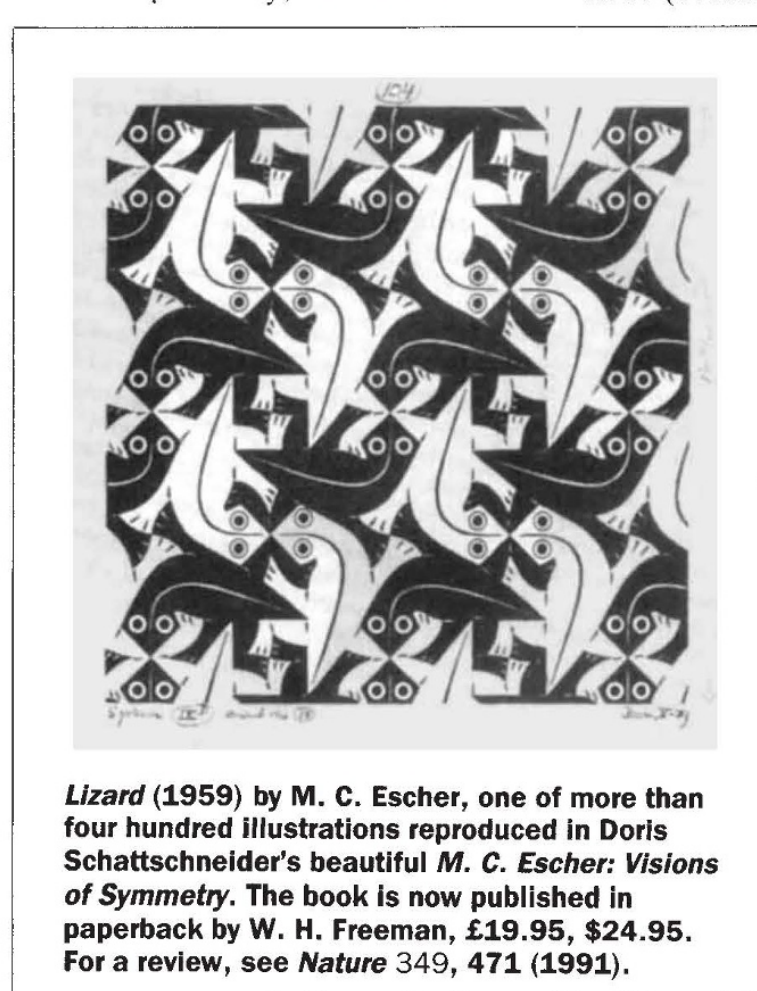


we have designed into it whatever properties of the nervous system give rise to consciousness) and the other is not. He cannot have it both ways - either consciousness has a function or it does not.

Searle is interesting and sound on intentionality, that is, the way in which all cognitive processes refer to entities. Underlying any belief or proposition are a vast number of other beliefs and unacknowledged assumptions. You cannot interpret the command "Sit on the chair" without the assumptions (perhaps never consciously made) that the seat is solid and that solid surfaces can support the human bottom. From his discussion of intentionality, he proceeds to attack the notion that there are unconscious thoughts that cannot in principle be made conscious. He would allow that a memory is mental even if it is not currently in consciousness, but he denies that there could be unconscious ideas that could never be brought to awareness, attacking in the process parts of Freudian theory. Although he does not mention him by name, he dismisses Helmholtz's idea of unconscious inference, as exhibited, for example, in our remarkable capacity to see depth using at least ten different cues.

Searle argues that the neural activity that results in conscious experience must be specified at a neurophysiological level and that it is vacuous to regard the brain as a digital computer, because everything from whirlwinds to leaves can be regarded as computers depending on the observer's point of view. His attack on cognitive science seems misguided. It is of course true that computer simulation may help us to understand the behaviour of whirlwinds. From a scientific point of view it is irrelevant whether the hypothetical variables postulated in attempts to understand brain function (such as David Marr's primal sketch and 21/2dimensional sketch) are or are not mental, provided they help us to understand at a high level of abstraction how the brain is working.

It is a pity that Searle ends with this sort of logic chopping, particularly as he gives no advice on what cognitive scientists should be doing other than what they are doing, except for an injunction that they should be more cautious in their claims and in their use of language. Indeed it is doubly a pity, for the last chapters mar a book that is almost always sensible and lucid, so much so indeed that it is likely to be ignored by that vast majority of potential readers who believe books on consciousness are only of interest if they make unintelligible departures from common sense.

Stuart Sutherland is in the Laboratory of Experimiental Psychology, University of Sussex, Brighton BN1 9QG, UK.

\section{Brian's brain}

Igor Aleksander

The Turing Option. By Harry Harrison and Marvin Minsky. Warner/Viking: 1992. Pp. 422. \$21.95, £14.99 (hbk); £8.99 (pbk).

MARVIN Minsky, a doyen of artificial intelligence (AI), may be remembered by some for his prediction, made in the early $1970 \mathrm{~s}$, that three to eight years from that time we would have a machine with the general intelligence of a human being. I have often wondered how he now feels about this prediction, which has evidently not come to pass. How has the wisdom accrued over 20 years of further thought dealt with this aberration of judgement? Perhaps one way of dealing with it is to make the prediction come true through a novel. The Turing Option, which Marvin Minsky has written with Harry Harrison of Make Room! Make Room! fame (the film version may be remembered as Soylent Green), is the story of the ultimate AI - how things might be in the 2020s had Minsky's prediction been true.

Brian Delaney, a brilliant Irishman, works in the United States for Megalobe, where he has just invented the "real" AI. But as he is about to demonstrate it, the megacrooks get into his lab, put a bullet in his head and steal the AI. Despite the bullet, Brian is not dead. The equally brilliant Dr Snaresbrook is called in to rebuild his brain, which she does using the latest micromanipulative technology, supercomputer implants and a deep knowledge of the way that a mind can be rebuilt by knowing a lot about the way it is related to the neural structure of the brain. It's not telling tales out of school to say that Brian not only recovers, but retraces his inventive steps and redesigns the AI. Will Brian and the AI catch the crooks? Will they develop AI products, become millionaires and live happily ever after? Oh, and one more thing about the plot, the AI becomes a tree-like robot with human charms and social skills. It objects to being called AI and becomes MI, Machine Intelligence ("there's nothing artificial about me").

My personal problem with science fiction of this kind is that knowing that one of the authors is an eminent scientist makes me aware of two plots, one scientific and the other literary. Even worse, it makes me expect the first of these to be at least scientifically interesting, if not always plausible. Unfortunately, the interesting scientific story gets dreadfully polluted with high-tech gimmickry. From the first few pages, the authors shower their readers with voice-sensing telephones, high-definition television con- ferencing, voice faxes and a host of other minor gadgets. No problem here with scientific plausibility, it's just the yawns that have to be suppressed. But digging past this high-tech veneer, the scientific plot touches on interesting points. Can the mind of a damaged brain be reconstructed by reconnecting the severed connections? Can the process be aided by implanting a microminiature computer in the brain? Brian discovers to his surgeon's delight and surprise that the computer in his brain not only serves to control some mental activity, but can also be accessed, and its memory contents become part of Brian's consciousness - that's definitely food for thought. Then there is Sven, or Machine Intelligence. He is given masses of silicon memory and that seems to be sufficient for him to become increasingly 'human' as the plot progresses. Is bulk memory what human intelligence is all about?

These debating points are probably the best there is about this novel. Unfortunately, the literary plot failed to capture my interest. Again it's the choking effect of high-technology that may be to blame. Sven the robot takes centre stage among the characters. It seems to have attracted all of the authors' capacity for characterization, leaving Brian and his human friends as rather wooden figures that have little in the way of humanity. Giving the benefit of the doubt, this may be part of the design. It makes the point that machines could be more human than humans. This may be subtle, but takes away from the pace and tension that might be expected from what the dust jacket promises will be "a thriller of hair-raising suspense".

There may well be readers who are thrilled by the thought of voice faxes and supersmart robots in a world where people slink into the background and are only worthwhile if they are capable of designing intelligent machines or performing extraordinary feats of mind surgery. My own literary needs for thrills and suspense are better served by the likes of John Le Carré or Len Deighton.

Igor Aleksander is in the Department of Electrical and Electronic Engineering, Imperial College of Science, Technology and Medicine, Exhibition Road, London SW7 2BT, UK.

A new edition of What Computers Still Can't Do by Hubert L. Dreyfus has just been published by MIT Press. In 1972 , this manifesto on the inherent inability of machines to mimic higher mental functions caused an uproar in the Al community.

Dreyfus has now added a lengthy introduction addressing the shift in the focus of research towards connectionism and neural networks. Price $\$ 27.50$, $£ 24.95$ (hbk); \$13.95, £12.50 (pbk). 